\title{
Culturas, políticas e práticas de inclusão na formação de professores em Educação Física: analisando as ementas.
}

\author{
Michele Pereira de Souza da Fonseca *
}

Mônica Pereira dos Santos **

\begin{abstract}
Resumo: $O$ presente artigo tem como objetivo analisar as ementas das disciplinas obrigatórias que compõe o currículo dos licenciandos do curso de Educação Física da UFRJ, observando se e como a inclusão é tratada durante sua formação. Para este fim, utilizamos como referencial de análise e discussão a estrutura conceitual sobre Inclusão, compreendida em três dimensões: a construção de culturas, o desenvolvimento de políticas e a orquestração de práticas inclusivas. No que tange a metodologia, realizamos a análise documental; dessa forma, pesquisamos as ementas de todas as 37 disciplinas obrigatórias que compõe o currículo dos licenciandos em Educação Física da Instituição pesquisada, e para a análise dos dados obtidos, utilizamos o método de Análise de Conteúdo. Nesse quadro geral da análise das ementas, observamos que os temas relativos à dimensão da orquestração de práticas inclusivas se apresentam em maior número $(36,36 \%)$. Muito emparelhados surgem os temas relativos à dimensão da criação de culturas inclusivas $(29,70 \%)$ e à dimensão biológica $(28,48 \%)$, e apenas $5,46 \%$ remetem a questões da dimensão do desenvolvimento de políticas inclusivas. Percebemos, então, que há uma enorme ênfase nas práticas, e grande preocupação com as questões físico-corporais e biológicas, em detrimento de um cunho político, fundamental para orientar uma formação crítica e reflexiva. Palavras-chave: Educação física: educação. Currículo. Equidade.
\end{abstract}

\section{INTRODUÇÃO}

A formação de professores tem sido um tema recorrente nas pesquisas, debates e literatura atuais, tanto em nível nacional quanto

\footnotetext{
* Licenciada em Educação Física. Mestre em Educação. Professora da Universidade Federal do Rio de Janeiro, Escola de Educação Física e Desportos. Doutoranda em Educação da UFRJ. Rio de Janeiro, Brasil E-mail: michelepereira22@yahoo.com.br

** Graduada em Psicologia. Professora Adjunta da Universidade Federal do Rio de Janeiro, Faculdade de Educação. Mestrado e doutorado em Psychology and Special Needs Education pela University of London, UK. Rio de Janeiro, RJ, Brasil. E-mail: monicapes@gmail.com
} 
internacional. A preocupação acerca desse assunto se dá, em geral, sob a proposição de uma formação crítica, reflexiva e comprometida, por conta de todas as responsabilidades que a profissão docente carrega. (FONSECA, 2009).

Por vivermos numa sociedade reconhecidamente plural (MOREIRA, 2002), em complemento as responsabilidades habituais que a profissão exige, o professor deve estar atento e ajustar o foco de trabalho e sua formação, respeitando e valorizando as questões que constituem a pluralidade dessa sociedade, que também são refletidas no âmbito educacional. Para isso, as diferenças não podem ser colocadas como obstáculos e sim como recursos que podem enriquecer as relações humanas e promover transformações.

Nesse sentido, o presente artigo tem como objetivo analisar as ementas das disciplinas obrigatórias que compõe o currículo dos licenciandos do curso de Educação Física da UFRJ, observando se e como a Inclusão é tratada durante sua formação.

Para este fim, utilizamos como referencial de análise e discussão a estrutura conceitual sobre Inclusão, compreendida em suas três dimensões: a construção de culturas, o desenvolvimento de políticas e a orquestração de práticas inclusivas, com a qual Santos (2003) e Booth e Ainscow (2002) vêm trabalhando desde os anos 80.

Inclusão é um termo relativamente recente, que apareceu em meados dos anos 90 e desde então tem sido alvo de bastante polêmica (SANTOS, 2003), podendo ser facilmente confundido ou colocado como sinônimo de termos como integração e educação especial.

Nesse estudo, buscamos operar com a idéia de Inclusão como um processo dialético, um conceito amplo, uma perspectiva de olhar que não privilegia somente uma parte da população; não se limita à simples inserção de pessoas rotuladas como diferentes num ambiente do qual têm sido excluídos e também não se restringe a algumas pontuais áreas da vida humana (SANTOS, 2003).

Consideramos a Inclusão como um processo. Em Educação, esse processo, que é sempre sem fim, busca envolver muitas mudanças objetivando promover a aprendizagem e participação plena de todos, como nos confirma Santos (2003, p.81):

Wovimento, Porto Alegre, v. 17, n. 01, p. 95-116, janeiro/março de 2011. 
[...] é uma luta, um movimento que tem por essência estar presente em todas as áreas da vida humana, inclusive a educacional. Inclusão se refere, portanto, a todos os esforços no sentido da garantia da participação máxima de qualquer cidadão em qualquer arena da sociedade em que viva, à qual ele tem direito, e sobre a qual ele tem deveres.

Procuramos entender os processos de inclusão/exclusão numa relação dialética um com o outro, tendo como ponto de partida a compreensão de que existem as dimensões de culturas, políticas e práticas de exclusão - para explicar esses fenômenos excludentes, e de inclusão - com possibilidade de propor intervenções inclusivas para minimizar ou combater as exclusões. Sob esse olhar, seria desaconselhável considerar contextos como definitivamente "inclusivos" ou "excludentes", pois tal representaria desconsiderar a historicidade dialética presente na relação inclusão/exclusão, que é, por isso mesmo, um processo, e não um fenômeno separável e passível de análise particularizada e descontextualizada. Sobre este assunto, Santos (1999-2000, p.48) nos confirma que:

Gera-se o mito de que uma vez atingidos certos objetivos e traçadas certas estratégias organizacionais e administrativas, a inclusão fica feita, fica completa. Perde-se, assim, o caráter dinâmico e dialético do processo que vai muito além, em suas raízes e evolução histórica, daquilo que pode ser visivelmente observado e feito de imediato.

A citada autora ainda reitera o caráter processual desse termo, afirmando que "nenhuma escola é inclusiva. Mas as escolas podem (e devem) estar incluindo". (SANTOS, 1999/2000, p.50, grifo do autor); e ainda aponta que a aplicação da ação no tempo gerúndio é intencional, de forma a denotar movimento constante no que tange ao aumento da participação e minimização da exclusão.

O caráter dialético desse processo inclusivo/excludente reflete o dinamismo com que se configuram, se constroem e se estabelecem as relações humanas. De acordo com Sawaia (2008, p.108):

Movimento, Porto Alegre, v. 17, n. 01, p. 95-116, janeiro/março de 2011. 


\section{Antigor Orifinais Michele Pereira de Souza da Fonseca et al.}

O que queremos enfatizar ao optar pela expressão dialética inclusão/exclusão é para marcar que ambas não constituem categorias em si, cujo significado é dado por qualidades específicas invariantes, contidas em cada um dos termos, mas que são da mesma substância e formam um par indissociável, que se constitui na própria relação. A dinâmica entre elas demonstra a capacidade de uma sociedade existir como um sistema.

De acordo com Souza Santos (2007), essa expressão é utilizada para explicitar as contradições e complexidades da exclusão social; trata-se de um conceito-processo capaz de indicar o movimento e não a essencialidade que as palavras exclusão e inclusão assumem no cenário contemporâneo.

Em complementação ao caráter dialético, Santos (2009) e Santos e Santiago (2009) têm se referido ao caráter também trialético da relação inclusão/exclusão. A ideia da trialética remete-nos à possibilidade de contemplarmos, em nossas análises, perspectivas que ultrapassem as visões binárias e polarizadas com as quais o racionalismo moderno acostumou-nos a trabalhar. Se a dialética aponta o dinamismo e a contradição (esta ainda concebida dentro de uma visão polarizada, que por mais real que seja, parece insuficiente para contemplar toda a complexidade dos fenômenos e relações humanas), a trialética aponta para a complexidade, a tensão, as forças em disputas e também a multiplicidade de possibilidades de análise e solução das problemáticas.

Graficamente, utilizamo-nos da triqueta, composta pela interseção de quatro figuras circulares, para representar o que tentamos dizer, conforme a figura abaixo:

Movimento, Porto Alegre, v. 17, n. 01, p. 95-116, janeiro/março de 2011. 


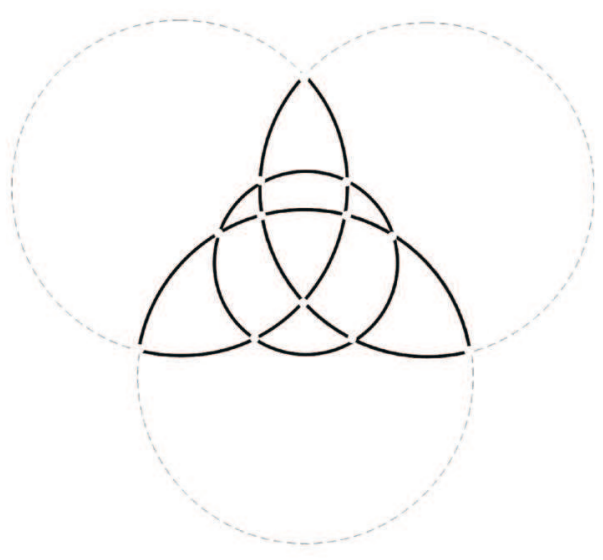

Figura 1: Triqueta

A triqueta parece-nos particularmente significativa porque, além de representar a infinita possibilidade simbolizada pela circularidade em um movimento descontínuo, intercambiável e espiralar, apresenta também certa harmonia quando vista em sua totalidade. Os cruzamentos dos pontos de interseção em aberto representam a possibilidade de que novos elementos adentrem as figuras, aumentando-a, tornando-a mais rica e variada, sem que por isso perca sua harmonia. Os trechos de interseção propriamente ditos representam os pontos em que as relações e fenômenos acontecem, conflituosamente ou não. Os três grandes círculos (cuja parte mais exterior é pontilhada, portanto sempre inacabada ou infindável), por sua vez, representam as três dimensões com as quais vimos explicando e analisando os processos de inclusão/exclusão: a da construção de culturas, do desenvolvimento de políticas e da orquestração das práticas de inclusão/exclusão em educação. Elas se encontram em vários momentos, tanto periféricos como "nucleares", dos processos de inclusão/exclusão, tornando-os mais ou menos complexos em sua compreensão e ação.

Com relação às dimensões, consideramos que a criação de culturas inclusivas abrange os valores, percepções, conceitos, representações, relações, sentimentos, interpretações e simbolismos que

Wovimento, Porto Alegre, v. 17, n. 01, p. 95-116, janeiro/março de 2011. 


\section{Artifos Orifinais Michele Pereira de Souza da Fonseca et al.}

os sujeitos atribuem às coisas na medida em que delas participam ou são marginalizados. Os valores, conceitos e princípios que embasam as culturas das instituições permitem a construção de percepções e de práticas discursivas que norteiam as decisões sobre as políticas e as práticas, e em conseqüência disso, essa instituição se desenvolve (ou não) num processo contínuo e se transforma (ou não) com vistas a alcançar a construção de uma comunidade estabelecendo valores inclusivos.

$\mathrm{O}$ desenvolvimento de políticas que propõem a inclusão ou minimização da exclusão é concretizado nas estratégias institucionais, nos documentos (no âmbito macro, meso ou micro) que regem as instituições, nos Projetos Político-pedagógicos, planejamentos de aula, nas regras ou acordos disciplinares ditos ou escritos, enfim, nas diretrizes e norteamentos das ações que buscam a inclusão. Essa dimensão se refere às participações sociais efetivas em relação à inclusão, ao fazer pedagógico de maneira a atender à diversidade de estudantes, ao que se constrói e se desconstrói dia após dia, no âmbito institucional.

De acordo com Booth et al (2000) apud Santos et al (2007, p.14), a dimensão da orquestração das práticas de inclusão está relacionada à preocupação em fazer com que as práticas das instituições educacionais:

\footnotetext{
[...] reflitam as culturas e políticas de inclusão da instituição [e] (...) assegurar que todas as atividades de sala de aula ou extra curriculares encorajem a participação de todos os alunos e baseiem-se em seus conhecimentos e experiências fora da instituição.
}

É importante ressaltar que as dimensões das culturas, políticas e práticas são verbalmente tratadas em separado por uma questão organizacional e para melhor entendimento sobre o que significa cada uma delas. Vale lembrar, entretanto, como vimos na figura acima, que nos referimos à Inclusão ou às dimensões citadas de uma maneira flexível e dinâmica; as dimensões se complementam e se inter-relacionam todo o tempo numa relação complexa.

Movimento, Porto Alegre, v. 17, n. 01, p. 95-116, janeiro/março de 2011. 


\section{DeCisões METOdológicas}

O presente estudo constitui uma pesquisa qualitativa, sob o ponto de vista da abordagem do problema, uma vez que foi realizada análise interpretativa de dados; no entanto, nos utilizamos de abordagens quantitativas como forma de complementar os procedimentos e os dados qualitativos. Não pretendemos, neste estudo, utilizar os dados estatísticos de forma pura, e sim, com objetivo de explorar as implicações dos resultados no contexto da pesquisa. Por isso, classificamos como uma pesquisa qualitativa, pois permite analisar os aspectos implícitos ao desenvolvimento das práticas organizacionais (TRIVIÑOS, 1987), utilizando-nos de números para complementar e ilustrar os resultados e fortalecer as interpretações.

\subsection{TÉCNICAS E INSTRUMENTOS DE COLETA DE DADOS}

Para a realização desta pesquisa, utilizamos a análise documental, para a qual utilizamos, então, as ementas de todas as 37 disciplinas obrigatórias que compõe o currículo dos licenciandos em Educação Física da Instituição pesquisada. Obtivemos esse material através da Secretaria de Graduação da Universidade.

$\mathrm{Na}$ pesquisa documental, utilizamos documentos originais, que ainda não receberam tratamento analítico por nenhum autor. Para Lüdke e André (1986, p.38) “[...] a análise documental pode se constituir numa técnica valiosa de abordagem de dados qualitativos, seja complementando as informações obtidas por outras técnicas, seja desvelando aspectos novos de um tema ou problema".

\subsection{PROCEDIMENTOS DE ANÁLISE DE DADOS}

Para a análise dos dados obtidos, utilizamos o método de Análise de Conteúdo (BARDIN, 1977, p.42), que segundo a autora citada:

É um conjunto de técnicas de análise das comunicações visando obter, por procedimentos sistemáticos e objetivos de descrição do conteúdo das mensagens (quantitativos ou não) que permitam a inferência de conhecimentos relativos às condições de produção/ recepção (variáveis inferidas) destas mensagens.

Movimento, Porto Alegre, v. 17, n. 01, p. 95-116, janeiro/março de 2011. 


\section{Artifos Orifinais Michele Pereira de Souza da Fonseca et al.}

AAnálise de Conteúdo é um instrumento de pesquisa empregado para ressaltar a existência de palavras, frases e expressões dentro de um texto ou conjunto de textos, de acordo com seu objetivo de pesquisa. Na presente pesquisa, analisamos os conteúdos descritos nas ementas das disciplinas.

Minayo (2001, p.74) enfatiza que a análise de conteúdo visa verificar hipóteses e/ou descobrir as entrelinhas do material pesquisado: “[...] o que está escrito, falado, mapeado, figurativamente desenhado e/ou simbolicamente explicitado, sempre será o ponto de partida para a identificação do conteúdo manifesto (seja ele explícito e/ou latente)".

Esse procedimento de análise organiza-se em torno de categorias. A categorização permite reunir grande número de informações, esquematizando e correlacionando classes de acontecimentos para organizá-los; dessa forma, representa "transformar" dados brutos em dados ordenados. Essa técnica se trata de um processo de classificação, colocação em gavetas ou caixas (BARDIN, 1977) e permite uma abordagem quantitativa no sentido de, após o agrupamento do material em diferentes categorias, construir uma tabela de frequencias (ou de porcentagens) dos enunciados assim classificados (L'ÉCUIER, 1999).

Essas categorias podem ser pré ou pós-definidas. A princípio, utilizaríamos categorias pré-definidas, que estão de acordo com a perspectiva teórica desse estudo, baseadas na dialética inclusão/ exclusão (BOOTH; AINSCOW, 2002; SANTOS, 2003), sendo elas: dimensão da construção de culturas inclusivas, dimensão do desenvolvimento de políticas inclusivas e dimensão de orquestração das práticas inclusivas, porém durante a leitura flutuante (BARDIN, 1977) das ementas, percebemos um grande número de palavras, frases e expressões que remetiam à parte fisiológica, anatômica, cinesiológica e bioquímica do ser humano.

Não pudemos ignorar essas informações que apareciam nessa primeira leitura, principalmente porque contamos 47 inferências. Assim sendo, para além das três categorias estabelecidas a priori de acordo com nossa perspectiva teórica, nomeamos a quarta categoria Dimensão biológica do ser humano para abarcar as inferências que remetiam à parte biológica do corpo humano. Trabalhamos, desse

Movimento, Porto Alegre, v. 17, n. 01, p. 95-116, janeiro/março de 2011. 
modo, no modelo misto, "onde o pesquisador conta com categorias preexistentes, porém abre espaço para que outras surjam no desenvolvimento de sua análise" (L'ÉCUIER, 1999, p.10).

Silva (2008,p.229), em sua tese ${ }^{1}$, analisou 12 ementas do curso de Licenciatura em Educação Física na mesma Instituição que pesquisamos, utilizando a técnica de Análise de Conteúdo e as mesmas três categorias a priori que utilizamos na presente dissertação. Aproveitando essa aproximação, nos baseamos nesse estudo e utilizamos as mesmas subcategorias que a autora estabeleceu em sua pesquisa: "Durante o processo de análise do conteúdo, as categorias mais amplas foram organizadas em subcategorias, a partir de temas identificados como sendo relevantes para o debate acerca da dialética inclusão/exclusão".

Conforme justificamos, acrescentamos a categoria Dimensão biológica do ser humano às categorias definidas a priori, e as subcategorias relativas a essa "nova" categoria foram elaboradas por nós, de acordo com a vivência na área e conhecimento das disciplinas. Desse modo, organizamos quatro categorias:

\begin{tabular}{|c|l|l|l|l|}
\hline Categorias & $\begin{array}{l}\text { Dimensão da cri- } \\
\text { ação de culturas } \\
\text { inclusivas }\end{array}$ & $\begin{array}{c}\text { Dimensão do } \\
\text { desenvolvmento } \\
\text { de políticas } \\
\text { inclusivas }\end{array}$ & $\begin{array}{c}\text { Dimensão de } \\
\text { orquestração } \\
\text { das práticas de } \\
\text { inclusão. }\end{array}$ & $\begin{array}{c}\text { Dimensão } \\
\text { biológica do } \\
\text { ser humano }\end{array}$ \\
\hline \multirow{2}{*}{$\begin{array}{c}\text { Sub } \\
\text { categorias }\end{array}$} & $\begin{array}{l}\text { Educação e } \\
\text { Educação Física: } \\
\text { perspectivas } \\
\text { históricas e sócio- } \\
\text { filosóficas }\end{array}$ & $\begin{array}{l}\text { Educação e } \\
\text { Educação Física: } \\
\text { aspectos legais, } \\
\text { éticos e deon- } \\
\text { tológicos }\end{array}$ & $\begin{array}{l}\text { Educação } \\
\text { Física: Métodos, } \\
\text { metodologias, } \\
\text { procedimentos }\end{array}$ & $\begin{array}{l}\text { Funcionamento } \\
\text { do corpo } \\
\text { humano }\end{array}$ \\
\cline { 2 - 6 } & $\begin{array}{l}\text { Educação e } \\
\text { Educação Física: } \\
\text { desenvolvimento } \\
\text { e aprendizagem } \\
\text { humanos }\end{array}$ & $\begin{array}{l}\text { Educação e } \\
\text { Educação Física: } \\
\text { aspectos político- } \\
\text { pedagógicos }\end{array}$ & $\begin{array}{l}\text { Educação Físi- } \\
\text { ca: Avaliação }\end{array}$ & $\begin{array}{l}\text { Técnico-instru- } \\
\text { menta }\end{array}$ \\
\hline
\end{tabular}

Quadro 1: quadro geral de categorias e subcategorias

${ }^{1}$ A tese intitulada "Criatividade e Inclusão na formação de professores: Representações e práticas sociais" teve como objeto a criatividade na prática pedagógica em sua relação com a inclusão em Educação. A autora utilizou como referencial de análise a dimensão das culturas, políticas e práticas inclusivas, e em uma parte de sua tese, comparou os cursos de Educação Física de duas Universidades, e analisou somente disciplinas constituintes das dimensões relação ser humano-sociedade e aspectos didático-pedagógicos.

Wovimento, Porto Alegre, v. 17, n. 01, p. 95-116, janeiro/março de 2011. 


\title{
104 Artifos Orifinais Michele Pereira de Souza da Fonseca et al.
}

Assim sendo, todas as palavras, frases e expressões presentes nas ementas que tinham potencial para remeter ao debate acerca da dialética inclusão/exclusão, foram classificados nessas categorias e suas correspondentes subcategorias.

A primeira categoria a ser analisada foi a dimensão da construção de culturas inclusivas, onde foram agrupadas palavras, frases e expressões que denotassem ações receptivas, colaboradoras e estimulantes, e que remetessem as discussões sobre respeito e diversidade, além de princípios e valores que pudessem orientar as políticas e as práticas do contexto institucional.

Essa dimensão foi organizada em duas subcategorias: Educação e Educação Física: perspectivas históricas e sócio-filosóficas e Educação e Educação Física: desenvolvimento e aprendizagem humanos. De acordo com Silva (2008, p.230):

\begin{abstract}
A subcategoria Educação e Educação Física: perspectivas históricas e sócio-filosóficas foi constituída por assuntos que dizem respeito à compreensão do papel da Educação e da Educação Física na construção da identidade e do sistema de valores dos diferentes povos, conteúdos esses que focam a influência dos aspectos históricos, sociais e filosóficos no contexto da formação humana e social.
\end{abstract}

Na subcategoria Educação e Educação Física: desenvolvimento e aprendizagem humanos, [...] foram classificados assuntos que tratam de aspectos voltados para a compreensão da diversidade humana no que diz respeito à aprendizagem e ao desenvolvimento" (SILVA, 2008, p.230).

A segunda categoria a ser analisada foi a dimensão do desenvolvimento de políticas inclusivas, onde agrupamos palavras, frases e expressões que remetessem à idéia de discutir sobre os objetivos ligados ao processo educacional de desenvolvimento da instituição e as intenções de formalizar esse processo visando atender a diversidade e apoiar a aprendizagem. Essa categoria foi organizada em duas subcategorias: Educação e da Educação Física: aspectos legais, éticos e deontológicos e Educação e da Educação Física: aspectos político-pedagógicos.

Movimento, Porto Alegre, v. 17, n. 01, p. 95-116, janeiro/março de 2011. 
A terceira categoria analisada foi a dimensão de orquestração das práticas de inclusão e foram agrupadas à ela as unidades de sentido que remetessem à discussão sobre o fazer pedagógico e "como esse processo de inclusão pode - ou - deve ser realizado no campo educacional" (SILVA, 2008, p. 229). Essa dimensão foi organizada em duas subcategorias: Educação Física: métodos, metodologias e procedimentos e Educação Física: avaliação.

A dimensão biológica do ser humano foi dividida em duas subcategorias: Funcionamento do corpo, onde agrupamos palavras, frases e expressões que remetiam às funções do organismo integrado aos sistemas, e sua relação com o ambiente interno e externo, e técnicoinstrumental, que se referia a procedimentos técnicos relacionados à área.

\section{ANÁLISE E dISCUSSÃo}

Para a realização da análise documental, utilizamos as ementas de todas as trinta e sete disciplinas obrigatórias do curso de Licenciatura em Educação Física da UFRJ. Justificamos a escolha por não incluir os programas das disciplinas nessa análise, porque o programa é flexível, quem define é o professor, já a ementa é fixa, quem define é a Universidade. O curso de Educação Física é composto atualmente de dezessete professores substitutos ${ }^{2}$, os quais modificam o programa frequentemente. Assim sendo, podemos analisar um documento que deve reger a disciplina e não adiantaria analisar, por exemplo, a bibliografia ou conteúdo de um programa que o professor nunca utilizou.

Nesta análise, não estamos usando as disciplinas compartimentadas por períodos, porque não acreditamos na Educação como compartimento e sim na formação integral do ser humano, na formação do cidadão (BRASIL, 1998).

Após a leitura preliminar das trinta de sete ementas, identificamos cento e sessenta e cinco temas que poderiam provocar debates

${ }^{2}$ Dados obtidos através da coordenação de graduação do curso.

Wovimento, Porto Alegre, v. 17, n. 01, p. 95-116, janeiro/março de 2011. 
106 Artigos Origimais Michele Pereira de Souza da Fonseca et al.

em relação à dialética inclusão/exclusão. A Tabela 01 apresenta os resultados dessa análise mais ampla:

Tabela 1: Quadro geral da análise das ementas

\begin{tabular}{ccc}
\hline Dimensões & $\mathbf{N}^{\circ}$ & $\mathbf{\%}$ \\
\hline $\begin{array}{c}\text { Dimensão da criação de } \\
\text { culturas inclusivas } \\
\text { Dimensão do desen- } \\
\text { volvimento de políticas } \\
\text { inclusivas } \\
\begin{array}{c}\text { Dimensão da orquestração } \\
\text { de práticas inclusivas }\end{array}\end{array}$ & 49 & $29,70 \%$ \\
$\begin{array}{c}\text { Dimensão biológica do ser } \\
\text { humano }\end{array}$ & 60 & $5,46 \%$ \\
\hline Tota & 47 & $28,48 \%$ \\
\hline
\end{tabular}

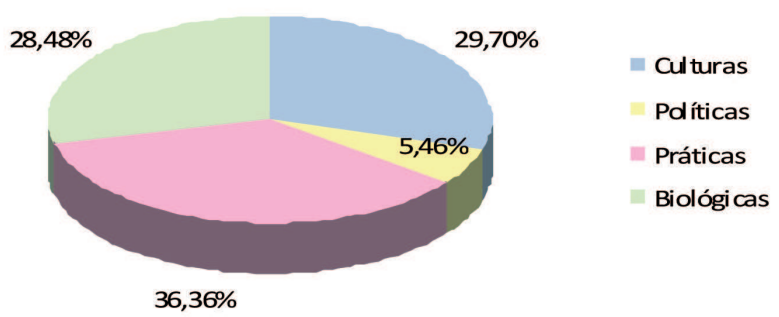

Gráfico 1: Análise das ementas

Nesse quadro geral da análise das ementas, observamos que os temas relativos à dimensão da orquestração de práticas inclusivas se apresentam em maior número $(36,36 \%$ - 60$)$. Muito emparelhados surgem os temas relativos à dimensão da criação de culturas inclusivas $(29,70 \%$ - 49) e à dimensão biológica $(28,48 \%$ - 47), e apenas $5,46 \%$ (9) remetem a questões da dimensão do desenvolvimento de políticas inclusivas.

A pesquisa intitulada "Ressignificando a Formação de Professores para uma Educação Inclusiva" (SANTOS, et al, 2007) investigou a formação de futuros professores de todas as licenciaturas da Universidade aqui pesquisada com relação a uma orientação inclusiva de educação, se baseando nas dimensões que utilizamos neste estudo. No processo de análise das ementas dos cursos de licenciatura fo-

Movimento, Porto Alegre, v. 17, n. 01, p. 95-116, janeiro/março de 2011. 
ram destacadas 241 palavras/expressões/frases, e assim como nesta dissertação, a dimensão da orquestração das práticas de inclusão apareceu em maior número (52,69\%). 7,05\% se referiam à dimensão da criação de culturas inclusivas e 40,24\% à dimensão do desenvolvimento de políticas inclusivas.

Durante o processo de Análise do Conteúdo, as categorias foram organizadas em subcategorias, conforme mostram as tabelas 02,03 , 04 e 05 .

Tabela 2: Dimensão da criação de culturas inclusivas - EMENTAS

\begin{tabular}{ccc}
\hline Subcategorias & $\mathbf{N}^{\circ}$ & $\%$ \\
\hline $\begin{array}{c}\text { Educação e Educação } \\
\text { Física: perspectivas históri- } \\
\text { cas e sócio-filosóficas }\end{array}$ & 43 & $87,76 \%$ \\
$\begin{array}{c}\text { Educação e Educação } \\
\text { Física: desenvolvimento e } \\
\text { aprendizagem humanos }\end{array}$ & 6 & $12,24 \%$ \\
\hline Total & $\mathbf{4 9}$ & $\mathbf{1 0 0 \%}$ \\
\hline
\end{tabular}

No que tange à dimensão da construção de culturas inclusivas, em termos quantitativos, é notório que a prioridade recai sobre as discussões que abrangem as perspectivas históricas e sócio-filosóficas da Educação e da Educação Física - 87,76\% (43), quando apenas $12,24 \%$ (6) remetem ao desenvolvimento e aprendizagem humanos.

Assim, podemos observar que o resultado que encontramos aqui, de certa forma se aproxima das intenções firmadas no Projeto Pedagógico do Curso - PPC (BRASIL, 2006, p.10), que espera que o aluno desenvolva "capacidade de interpretar e problematizar, com autonomia, a realidade educacional em diferentes contextos históricos, sociais e econômicos". Além disso, ainda está descrito no citado documento que é necessário os estudantes tenham:

[...] consciência de seu papel como educador, sendo capaz de intervir pedagógica e profissionalmente junto às diferentes manifestações das culturas das atividades físicas e dos esportes, levando em consideração a diversidade do público alvo (BRASIL, 2006, p.15)

Wovimento, Porto Alegre, v. 17, n. 01, p. 95-116, janeiro/março de 2011. 
108 Artifor Originais Michele Pereira de Souza da Fonseca et al.

Nessa análise, pudemos constatar que as palavras, frases e expressões que remetem à dimensão da construção de culturas inclusivas encontradas nas ementas, oportunizam discussões nesse sentido, possibilitando compreender o contexto sócio-históricocultural da diversidade.

Notamos um aspecto interessante com relação às disciplinas que estão classificadas no PPC como Culturais do movimento humano. São disciplinas eminentemente práticas, mas que, ao que conste na ementa, têm preocupação em discutir aspectos de origem e evolução da modalidade e também o contexto sócio-histórico-cultural.

Podemos notar ainda que esses $12,24 \%$ (6) de temas que remetem à subcategoria Educação e Educação Física: desenvolvimento e aprendizagem humanos aparecem em três disciplinas, a maior parte (quatro inferências) na disciplina Psicologia da Educação. Percebemos assim que o currículo se mostra carente de uma disciplina que abarque a questão da aprendizagem/desenvolvimento motor, por exemplo, que somadas aos conteúdos da Psicologia da Educação, seriam de grande valia para a formação do licenciando.

Tabela 3: dimensão do desenvolvimento de políticas inclusivas - ementas

\begin{tabular}{ccc}
\hline Subcategorias & $\mathbf{N}^{\circ}$ & $\mathbf{\%}$ \\
\hline Educação e Educação & 3 & $33,33 \%$ \\
$\begin{array}{c}\text { Física: aspectos legais, } \\
\text { éticos e deontológicos }\end{array}$ & & \\
$\begin{array}{c}\text { Educação e Educação } \\
\text { Física: aspectos político- } \\
\text { pedagógicos }\end{array}$ & 6 & $66,67 \%$ \\
\hline Total & $\mathbf{9}$ & $\mathbf{1 0 0 \%}$ \\
\hline
\end{tabular}

De acordo com essa Análise, com relação à dimensão do desenvolvimento de políticas inclusivas, apontamos para a pouca preocupação em discutir aspectos relativos ao desenvolvimento de políticas inclusivas - apenas 5,46\% (9) do resultado geral - embora o PPC (Brasil, 2006, p.10) aponte para "a busca cotidiana e sistemática de compreensão da complexidade da prática pedagógica, nela incluídos os processos de ensino-aprendizagem e as questões de currículo e ensino e os fatores políticos, econômicos, sociais e culturais que afetam a vida escolar". Essa citação nos remete principalmente aos

Movimento, Porto Alegre, v. 17, n. 01, p. 95-116, janeiro/março de 2011. 
aspectos político-pedagógicos $(66,67 \%$ - 6), que apesar de pouco explorado nas ementas, ainda apareceram mais que os aspectos legais, éticos e deontológicos da Educação e Educação Física (33,33\% - 3). Nesse sentido, Silva (2008, p.231-232) ressalta que:

Uma importante questão coloca-se aqui: o desenvolvimento de políticas de inclusão, através das quais toda a escola possa se engajar para aumentar a aprendizagem e a participação de todos os estudantes requer a compreensão de como as políticas educacionais mais amplas se articulam e, em alguns casos, determinam o contexto político-pedagógico da escola.

Assim, seria importante voltar o olhar para essas questões político-educacionais mais amplas e estimular as discussões mais profundas sobre LDB, PCNs, e para além delas; e proporcionar que o licenciando " [...] possua uma ampla visão da realidade social, política, cultural e econômica do País, consciente das reais necessidades e possibilidades do cidadão" (BRASIL, 2006, p.16), conforme prega o PPC.

Tabela 4: dimensão da orquestração de práticas inclusivas - ementas

\begin{tabular}{ccc}
\hline Subcategorias & $\mathbf{N}^{\circ}$ & $\mathbf{\%}$ \\
\hline $\begin{array}{c}\text { Educação Física: Métodos, } \\
\text { metodologias, procedi- } \\
\text { mentos }\end{array}$ & 58 & $96,67 \%$ \\
Educação Física: Avaliação & 2 & $3,33 \%$ \\
\hline Total & $\mathbf{6 0}$ & $\mathbf{1 0 0 \%}$ \\
\hline
\end{tabular}

No que tange à orquestração de práticas inclusivas, a referida dimensão obteve a maior porcentagem - 36,36\% (60) - em todas as ementas analisadas. É notório que, com esse resultado, podemos pensar que a prática pela prática se estabelece majoritariamente nesse curso, principalmente as questões relativas a métodos, metodologias e procedimentos da Educação Física, que abrangem um total de $96,67 \%$ (58) das palavras, frases ou expressões nesta dimensão, seguido de apenas 3,33\% (2) relativos à Avaliação.

Quando se considera a dimensão da orquestração de práticas de inclusão, cabe atentar para o fato de que não basta dominar uma infinidade de métodos

Movimento, Porto Alegre, v. 17, n. 01, p. 95-116, janeiro/março de 2011. 
110 Artifos Origimais Michele Pereira de Souza da Fonseca et al.

e técnicas para que a inclusão "dê certo". Toda e qualquer prática pedagógica está atrelada a valores e intenções políticas. O grande desafio é talvez, desvelar e problematizar que valores são esses e estabelecer as bases para ações políticas refletidas que incentivem os futuros professores à transformação das realidades de exclusão predominantes na sociedade atual (SILVA, 2008, p.234)

Nesse sentido, pode ser que, com esse grande percentual da citada dimensão, sejam desenvolvidas metodologias de trabalho que levem em conta as vivências, anseios e valores dos licenciandos e que não seja voltado somente para a ênfase na capacitação técnica, pois na perspectiva que trabalhamos, "[...] a educação inclusiva traz uma contribuição para uma educação diferente, transformadora, que vai além da visão neoliberal de capacitação" (SANTOS; PAULINO, 2008, p.14).

Tabela 5: dimensão biológica do ser humano - ementas

\begin{tabular}{ccc}
\hline Subcategorias & $\mathbf{N}^{\circ}$ & $\%$ \\
\hline $\begin{array}{c}\text { Funcionamento } \\
\text { do corpo humano } \\
\text { Técnico-instrumental }\end{array}$ & 43 & 91,49 \\
\hline Total & 4 & 8,51 \\
\hline
\end{tabular}

A Análise de Conteúdo nos mostrou que 28,48\% (47) das ementas refletem a dimensão biológica do ser humano; e pelo que observamos, abre pouco espaço para discussões acerca da dialética inclusão/exclusão, e reforçam a prática pela prática, que observamos na dimensão anterior.

Sabemos que num curso de Educação Física, as questões biológicas constituem parte importante, mas não se pode esquecer que lidamos com uma diversidade enorme de pessoas, que não são automatizadas ao movimento e ao funcionamento de seu próprio corpo; que para além de suas potencialidades e limites fisiológicos e biomecânicos, tem suas potencialidades e limites psicológicos e isso deve ser bem equilibrado - vimos esses percentuais bem parelhos referente à dimensão das culturas $(29,70 \%$ - 49) e referente à dimensão biológica $(28,48 \%$ - 47$)$.

Movimento, Porto Alegre, v. 17, n. 01, p. 95-116, janeiro/março de 2011. 
Não discutimos aqui o valor das disciplinas que compõem essa dimensão, mas sim, que estas poderiam ser voltadas para o público alvo que os licenciandos encontrarão nos estabelecimentos de ensino, ao se formarem - alunos: crianças e adolescentes em sua maioria lembrando que esses não são/serão atletas.

\section{ConsideraçõES FINAIS}

Quando nos propusemos a pesquisar a dimensão da construção de culturas inclusivas; a dimensão do desenvolvimento de políticas inclusivas e a dimensão de orquestração das práticas inclusivas (BOOTH ; AINSCOW, 2002; SANTOS, 2003) na formação de professores de Educação Física, não tivemos o objetivo de entrar na instituição e simplesmente apontar o que é inclusivo ou não, e sim, de investigar, de ouvir e de observar as pessoas que circulam, as culturas que permeiam, as políticas que influenciam, e as práticas que se estabelecem naquele lugar. De modo algum tivemos uma visão apriorística de Inclusão, nem tão pouco de Exclusão, embora tenhamos nosso direito de leitura.

Dessa forma, é importante retomarmos o objetivo desse estudo, que teve o intuito de analisar as ementas das disciplinas observando se e como a Inclusão, tal como definimos, é tratada durante a formação do licenciando. Especificamente sobre esse termo, percebemos que expressões como Inclusão ou Inclusão em Educação não aparecem explicitamente em nenhuma das trinta e sete ementas investigadas.

Embora tenha sido bastante expressivo, na análise das ementas, a ênfase nas práticas $(36,36 \%$ - 60), notamos um grande potencial a ser explorado relativo às culturas $(29,70 \%$ - 49), podendo contribuir significativamente para a construção de culturas inclusivas na pesquisada instituição.

Em contrapartida, o baixo percentual da dimensão do desenvolvimento de políticas inclusivas $(5,46 \%$ - 9) chamou a atenção para a pouca preocupação em apresentar temas que possibilitem discussões políticas, principalmente em se tratando de um curso de formação de professores. Consideramos que essas questões são muito importantes para entendermos a estrutura e funcionamento do sistema

Movimento, Porto Alegre, v. 17, n. 01, p. 95-116, janeiro/março de 2011. 


\section{Antigor Originais Michele Pereira de Souza da Fonseca et al.}

onde os licenciandos atuarão, já que, com o diploma de Licenciatura em Educação Física nas mãos, só têm habilitação para trabalhar no Ensino Básico (BRASIL, 2002).

Esse baixo percentual na dimensão das políticas se torna mais preocupante se comparado ao número da dimensão biológica do ser humano $(28,48 \%$ - 47); mais uma vez, deixa clara a enorme ênfase nas práticas e a preocupação com as questões físico-corporais, de rendimento e biologizantes, em detrimento de um cunho político, fundamental para orientar uma formação crítica e reflexiva.

Movimento, Porto Alegre, v. 17, n. 01, p. 95-116, janeiro/março de 2011. 
Cultures, policies and practices for inclusion in teacher education in physical education: analyzing the menus

Abstract: This article aims to analyze the menus of compulsory subjects that make up the curriculum for the initial education of future teachers of Physical Education at UFRJ, and observing whether the inclusion is treated during its formation. To this end, we used as reference for analysis and discussion of the conceptual framework on inclusion and included three dimensions: the construction of culture, policy development and orchestration of inclusive practices. Regarding the methodology, we conducted the document analysis, thus we studied the menus of all 37 required subjects that comprise the curriculum for future teachers in Physical Education Institution searched, and the data analysis, we used the method of analysisContent. In this general analysis of menus, we noticed that the issues concerning the size of the orchestration of inclusive practices are present in greater numbers $(36.36 \%)$. Paired very issues arise concerning the extent of creating inclusive cultures $(29.70 \%)$ and the biological dimension $(28.48 \%$ ) and only $5.46 \%$ of the questions refer to the size of the development of inclusive policies. We realized then that there is a huge emphasis on practice, and great concern with issues physical, biological and physical, to the detriment of a political nature, fundamental guide to training a critical and reflective.

Keywords: Physical education: education. Curriculum. Equity.

Movimento, Porto Alegre, v. 17, n. 01, p. 95-116, janeiro/março de 2011. 


\section{Artigor Origimais Michele Pereira de Souza da Fonseca et al.}

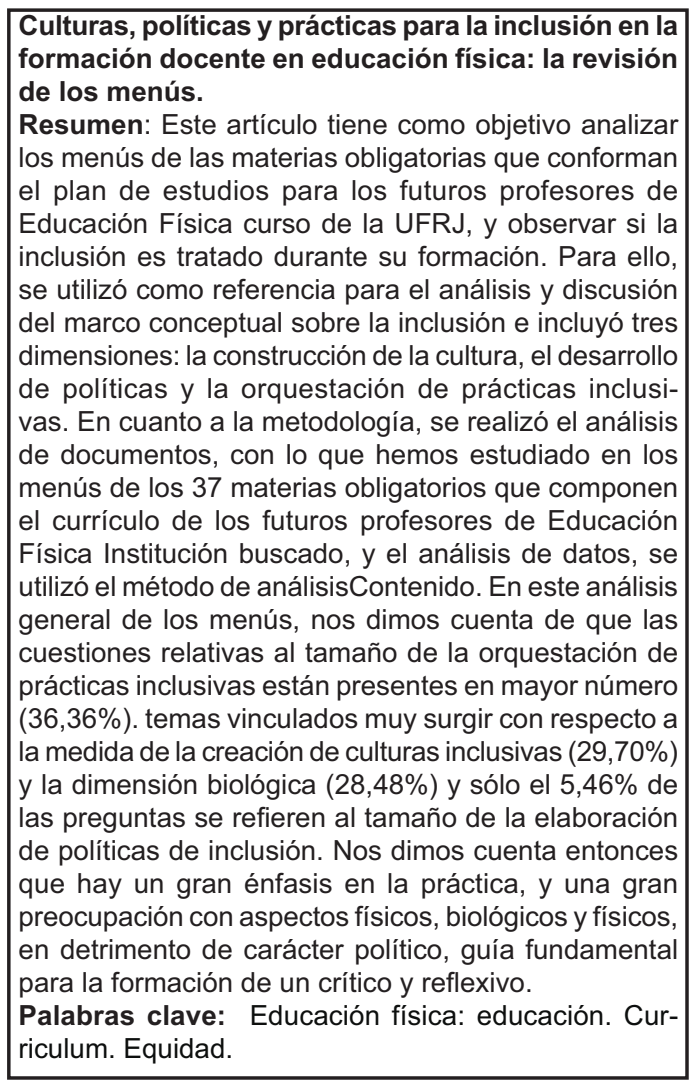

\section{REFERÊNCIAS}

BARDIN, Laurence. Análise de Conteúdo. Lisboa: edições 70, 1977

BOOTH, Tony; AINSCOW, Mel. Index para a inclusão: desenvolvendo a aprendizagem e a participação na escola. Traduzido por: Mônica Pereira dos Santos. Rio de Janeiro: LaPEADE, 2002.

BRASIL. Universidade Federal do Rio de Janeiro. Projeto pedagógico: licenciatura em Educação Física. Rio de Janeiro, 2006

BRASIL. Secretaria de Educação Fundamental. Parâmetros Curriculares Nacionais: terceiro e quarto ciclos: educação física/Secretaria de Educação Fundamental. Brasília: 1998.

Mavimento, Porto Alegre, v. 17, n. 01, p. 95-116, janeiro/março de 2011. 
BRASIL. Resolução CNE/CP 1, de 18 de fevereiro de 2002. Institui Diretrizes Curriculares Nacionais para a Formação de Professores da Educação Básica, em nível superior, curso de licenciatura, de graduação plena. Diário Oficial [da] República Federativa do Brasil, Poder Executivo. Seção I, p. 8-9, Brasília, DF, 4 mar. 2002.

FONSECA, Michele Pereira de Souza da. Inclusão: culturas, políticas e práticas de inclusão na formação de professores de Educação Física da UFRJ. 264 f. Rio de Janeiro, 2009. Dissertação (Mestrado em Educação). Faculdade de Educação, Universidade Federal do Rio de Janeiro, Rio de Janeiro, 2009.

L'ÉCUIER, René. Méthodologie de L'analyse développementale de contenu. In: KASZAP, Margot. Introduction à l'analyse qualitative. Quebec: Université Laval, , 1999.

LÜDKE, Meng; ANDRÉ, Marli E. D. A. Pesquisa em educação: abordagens qualitativas. São Paulo: Pedagógica e Universitária, 1986.

MINAYO, Maria Cecília de Souza (org). Pesquisa social: teoria, método e criatividade. Petrópolis/RJ: Vozes, 2001.

MOREIRA, Antônio Flávio Barbosa. Currículo, diferença cultural e diálogo. Revista Educação \& Sociedade, Campinas: v. 23, n. 79, p. 15-38, ago.2002

SANTOS. Mônica Pereira dos. O papel do ensino superior na proposta de uma educação inclusiva. Revista da Faculdade de Educação da UFF, Niterói, n. 7.p.7891, maio 2003.

SANTOS, Mônica Pereira dos. Desenvolvendo Políticas e Práticas Inclusivas "Sustentáveis": uma Revisita à Inclusão. Educação em foco, Rio de Janeiro, v. 4, n.2, p.47-56, set/fev.1999/2000.

SANTOS, Monica Pereira dos, et. al. Ressignificando a formação de professores para uma educação inclusiva. Relatório final de pesquisa apresentado a Capes. Rio de Janeiro: LaPEADE/UFRJ, 2007.

SANTOS, Mônica Pereira do; PAULINO, Marcos Moreira (orgs). Inclusão em educação: culturas, políticas e práticas. 2.ed.São Paulo: Cortez, 2008.

SANTOS, Mônica Pereira dos; SANTIAGO, Mylene Cristina. As múltiplas dimensões do currículo no processo de inclusão/exclusão em educação. In:COLÓQUIO INTERNACIONAL DE POLITICAS E PRÁTICAS CURRICULARES: DIFERENÇAS NAS POLÍTICAS DE CURRÍCULO, 4. 2009. Anais.....João Pessoa, PB, 2009. Recurso eletrônico..

SAWAIA, Bader B.(Org.). As artimanhas da exclusão: análise psicossocial e ética da desigualdade social. Petrópolis:Vozes, 2008.

SOUZA SANTOS. Boaventura. A queda do Angelus Novus: Para além da equação moderna entre raízes e opções. São Paulo: CEBRAP,1997.

SILVA, Kátia Regina Xavier da. Criatividade e inclusão na formação de professores: Representações e Práticas Sociais. 421 f, 2008. Tese (Doutorado). Universidade Federal do Rio de Janeiro, 2008.

Movimento, Porto Alegre, v. 17, n. 01, p. 95-116, janeiro/março de 2011. 
116 Artifos Origimais Michele Pereira de Souza da Fonseca et al.

TRIVIÑOS, Augusto N. S. Introdução à pesquisa em ciências sociais: a pesquisa qualitativa em educação. São Paulo: Atlas, 1987.

Recebido em: 29.07.2010

Aprovado em: 13.02. 2011

Movimento, Porto Alegre, v. 17, n. 01, p. 95-116, janeiro/março de 2011. 